\title{
Modelos de governação do risco. Análise comparativa entre três sistemas nacionais de proteção civil
}

Risk Governance Models. Comparative Analysis between Three National Civil Protection Systems

Modèles de gestion de risque. Analyse comparative entre trois systèmes nationaux de protection civile

Manuel João Ribeiro

\section{OpenEdition}

\section{Journals}

Edição electrónica

URL: http://journals.openedition.org/rccs/9533

DOI: $10.4000 /$ rccs.9533

ISSN: 2182-7435

\section{Editora}

Centro de Estudos Sociais da Universidade de Coimbra

Edição impressa

Data de publição: 1 dezembro 2019

ISSN: 0254-1106

\section{Refêrencia eletrónica}

Manuel João Ribeiro, « Modelos de governação do risco. Análise comparativa entre três sistemas nacionais de proteção civil », Revista Crítica de Ciências Sociais [Online], 120 | 2019, posto online no dia 12 dezembro 2019, consultado o 14 dezembro 2019. URL : http://journals.openedition.org/rccs/9533 ; DOI : 10.4000/rccs.9533 


\section{Modelos de governação do risco. Análise comparativa entre três sistemas nacionais de proteção civil*}

Os processos de governação do risco são importantes fatores explicativos das políticas públicas que os Estados adotam na prossecução das suas estratégias de segurança. Partindo de uma interrogação inicial em saber qual, ou quais, as formas de governação do risco que prevalecem na definição e caraterização dos sistemas de proteção civil, desenvolveu-se uma proposta teórico-analítica de quatro modelos: diretivo, hierárquico, descentralizado e cooperativo. Esta modelação, de cunho ideal-típica, foi aplicada ao estudo dos sistemas de proteção civil do Reino Unido, França e Portugal através de uma análise comparativa dos respetivos domínios e dimensões operativas. Os resultados e as conclusões desse trabalho de investigação, confrontando a análise empírica com os modelos tipológicos criados, constitui a finalidade deste artigo.

Palavras-chave: cidadania; gestão do risco; políticas públicas; proteção civil.

\section{Introdução}

Os processos de governação do risco são importantes fatores explicativos das opções e orientações adotadas pelos Estados na prossecução das suas estratégicas de segurança, constituindo-se, como tal, em indicadores fundamentais de análise das políticas públicas da organização e funcionamento dos respetivos sistemas de proteção civil.

Este artigo evidencia a pesquisa desenvolvida em relação ao estudo dos modelos de governação do risco, numa análise comparativa entre três sistemas de proteção civil: Reino Unido, França e Portugal.

Como interrogação inicial colocou-se a questão de saber qual, ou quais, os modelos de governação do risco que predominam na definição e caraterização dos sistemas de proteção civil. A investigação, contudo, não se circunscreveu,

* Este artigo foi escrito com base na investigação realizada para a tese de doutoramento no programa interuniversitário Território, Risco e Políticas Públicas, defendida pelo autor em 2018. 
exclusivamente, a uma abordagem em torno da gestão das catástrofes. A pesquisa foi direcionada, analiticamente, para a incorporação de uma visão transversal dos processos de governação, optando-se por um entendimento mais abrangente, e menos restritivo, dos sistemas de proteção, incluindo os indispensáveis mecanismos que decorrem das políticas, não apenas na gestão das catástrofes, mas também na gestão do risco. Conforme refere Britton (2007) na sua abordagem sobre o planeamento e a resposta dos sistemas nacionais aos desastres, embora a gestão das catástrofes continue a ser o problema central da intervenção desses sistemas, esse não é, nem pode ser, o seu único campo de ação, devendo alargar-se a outros domínios. A evidência e a avaliação dos acontecimentos vividos em Portugal nos incêndios de 17 de junho e de 15 de outubro de 2017, com as suas consequências catastróficas, são um exemplo da importância analítica desta dupla consideração integrativa, não só numa leitura interpretativa subsequente aos acontecimentos, mas também, e sobretudo, como mecanismo de lições apreendidas de modo a evitar a repetição dos erros e lacunas encontradas que, enquanto causas sistémicas, estiveram por detrás dessas catástrofes.

No processo de investigação, abordaram-se dois grandes eixos explicativos dos mecanismos de governação do risco que se complementam entre si:

- As políticas públicas de segurança prosseguidas pelos Estados, direcionando a análise para as relações intergovernamentais, nos domínios políticos e técnicos, em relação aos níveis de articulação entre a administração central e local, mediados, consoante os casos, pelos respetivos graus intermédios, regionais e distritais;

- Os processos de envolvimento dos cidadãos e stakeholders relacionados, diretamente ou não, com as políticas de segurança, procurando perceber a forma como os sistemas encaram, e incorporam, a participação da sociedade civil nas suas orientações e ações em defesa das próprias populações o que, como se sabe, constitui a narrativa discursiva predominante dos poderes, e das políticas públicas, em relação aos objetivos dos sistemas de segurança em proteção civil.

Tendo por suporte um quadro matricial que interseta as componentes do padrão político e da cidadania, foi desenvolvida uma proposta teórico-analítica de quatro modelos tipológicos de governação do risco - diretivo, hierárquico, descentralizado e cooperativo - para enquadramento dos subsequentes resultados da pesquisa e respetiva análise empírica.

Os objetivos centraram-se em perceber como surgiram, desenvolveram e se estruturam os atuais sistemas de segurança em proteção civil nos três países da União Europeia referidos, previamente selecionados para esta investigação. 
Para tal, foram contempladas quatro grandes dimensões analíticas:

- Primeiro, uma abordagem aos contextos políticos da governação, nas suas especificidades históricas, geográficas, culturais e sociais como matriz explicativa do tipo de sistemas em causa: se mais prescritivos ou mais colaborativos;

- Segundo, o questionamento relativo à forma como são exercidos os direitos e os deveres dos cidadãos nas políticas públicas de proteção civil: se numa ótica mais inclusiva ou numa mais exclusiva;

- Terceiro, perceber como são concetualizados os desastres/catástrofes: se atribuíveis a agentes externos ou se decorrentes de processos internos de organização social;

- Quarto e último, identificar que modelos de gestão operacional predominam nos respetivos sistemas: se modelos mais verticalizados de comando e controlo ou mais horizontais de cooperação e coordenação.

Resultantes deste enquadramento, três grandes hipóteses de trabalho foram colocadas, servindo, não só como contextualização e delimitação da pesquisa, como também enquanto monitorização e controlo face à finalidade definida de saber quais os modelos predominantes de governação do risco nos países em investigação.

A primeira hipótese centrou-se na afirmação de que os modelos de governação do risco e os sistemas organizacionais da proteção civil são influenciados, quer pela cultura política do país, quer pela história dos acontecimentos catastróficos neles registados.

Antecipando sinteticamente as primeiras conclusões, saliente-se serem inequívocos os resultados alcançados, comprovando-se os pressupostos levantados. Efetivamente, quer as culturas políticas, quer os acontecimentos catastróficos moldam os modelos de governação do risco e, por inerência, as suas consequências e efeitos repercutem-se nos respetivos sistemas de segurança e de proteção civil.

A segunda hipótese considerou que as políticas públicas dos sistemas de proteção civil reproduzem, tendencialmente, em relação aos escalóes governamentais inferiores, uma lógica centralizadora e burocrática que carateriza genericamente a administração central do Estado.

Do mesmo modo, embora com distintas formulações entre os três sistemas, a comprovação da afirmação também se manifestou correta. Evidenciam-se lógicas administrativas e burocráticas, de cunho prescritivo e diretivo, por parte das administrações centrais relativamente aos escalões inferiores da administração pública, corroborando assim a hipótese levantada.

Contemplou-se na terceira e última hipótese, que as narrativas e as representações sociais sobre a proteção civil consideram esta área de atividade como 
um dominio que, devido à sua especificidade e tecnicidade, apenas deve ser objeto da ação de especialistas, dificultando a participação e o envolvimento dos cidadãos e da sociedade civil.

Embora também confirmada, esta hipótese apresentou-se mais ambivalente, pois se, por um lado, as narrativas apontam para a importância de uma participação pública, por outro, contudo, a definição dos programas e, sobretudo, as ações no domínio operacional são encaradas como território especializado, apenas ao alcance de técnicos e peritos na área.

$\mathrm{Na}$ estrutura desta exposição serão observadas duas grandes componentes. Como suporte teórico da investigação, salienta-se o processo de construção e de definição dos modelos ideal-típicos de governação do risco que enquadram, analiticamente, as políticas públicas de segurança, identificando os processos de organização e funcionamento dos respetivos sistemas de proteção civil. Resultante do trabalho empírico, discutem-se as principais conclusões havidas, quer em relação a cada um dos países individualmente considerados, quer numa leitura comparativa entre eles, quer, ainda, na sua confrontação com os modelos analíticos de governação do risco desenvolvidos.

\section{Risco e governação: a governação do risco como domínio de investigação}

A pesquisa centrou-se, inicialmente, numa discussão crítica em torno dos principais conceitos que a suportaram. Transversal a toda a investigação, encontram particular ênfase as noções de risco e de governação. De qualquer modo, tal não hipoteca a inclusão de um conjunto de conceções associadas aos mesmos, e que acompanham, em permanência, a sua própria formulação e construção.

Em relação ao conceito de risco salienta-se a sua dupla concetualização enquanto probabilidade e incerteza. Como referem Aven e Renn (2010: 2; tradução do autor): "Não existe concordância na definição de risco. Estudando a literatura de risco, verificamos que o conceito é utilizado como valor esperado, como distribuição de probabilidades, como incerteza e como um evento". Constata-se, assim, e de acordo com estes investigadores, por um lado, a consideração do risco enquanto "expressão de probabilidades e de valores esperados" e, por outro, o relacionamento do "conceito com as consequências e as incertezas" (ibidem: 3; tradução do autor). Assumidamente, há uma opção clara pela recusa de visões ontológicas que prevalecem sobre o conceito, acentuando a sua condição epistemológica e, portanto, uma perspetiva construtivista na sua definição. Ou seja, o risco não é uma condição natural intrínseca, um "estado objetivo do mundo" (ibidem: 3-4; tradução do autor), antes resulta do conhecimento e da perceção que sobre 
ele se tem, enquanto processo que deriva da articulação entre o sistema social e o ambiente construído (Quarantelli, 1998), nas suas variadas dimensões explicativas e analíticas.

Relativamente à noção de governação, há numa conceção próxima de governança, entendida enquanto processos de gestão e de tomada de decisão coletivos onde, para além da participação das instituições e dos agentes de âmbito governamental, também se considera o envolvimento de outros atores e protagonistas não-governamentais - stakeholders e sociedade civil, por exemplo - nas respetivas medidas e ações a prosseguir. No conceito de governação, contudo, assume-se uma incorporação de práticas políticas institucionais mais estatocêntricas no exercício do poder e, inerentemente, de menor participação pública. Promoveu-se, assim, a sua decomposição, enquadrando a análise junto de noções consideradas da mesma família concetual, tais como regulação do risco e, também, de gestão - neste último caso nas vertentes do risco, emergência e desastre, identificando as analogias e as diferenças entre elas, numa formulação sistematizadora como matriz abrangente e definidora das políticas públicas de segurança em proteção civil. Uma referência especial ao contributo da matriz de governação do risco do IRGC - International Risk Governance Council (IRGC, 2005, 2008), que se constituiu como um dos referenciais decisivos para o posterior desenvolvimento dos modelos tipológicos de governação do risco.

Ainda dentro do respetivo enquadramento teórico, e assumindo uma importância contextualizadora enquanto suporte metateórico do desenvolvimento e análise empírica dos três sistemas em análise, salienta-se, pelo seu significado, a abordagem realizada a três grandes perspetivas sociológicas sobre o risco. As teorias da sociedade de risco de Beck (2009), a governamentalidade e biopolítica de Foucault (2008) e a abordagem cultural e simbólica de Douglas $(1992,2007)$. Os contributos principais destas três perspetivas sobre o risco são inequívocos, identificando-se, numa pequena síntese, as seguintes anotações:

- Em Beck (2009) são evidenciadas as mudanças operadas entre a primeira modernidade (modernidade precoce) e a sua segunda fase (modernidade tardia), com reflexo na própria compreensão da evolução dos sistemas de segurança em proteção civil. A pertença à União Europeia, com o disposto no Tratado de Lisboa, direciona a proteção civil para âmbitos mais supranacionais, com consequências tanto internas como externas nos mecanismos de governação.

- Relativamente a Foucault (2008) salienta-se a interessante e útil definição histórica dos tipos de governamentalidade, constituindo um importante referencial de enquadramento em relação aos três países, 
num percurso, de acordo com as caraterísticas políticas, económicas e sociais, pós-razão do Estado e aproximando-se, ou mesmo situando-se, no âmbito híbrido dos poderes liberais e neoliberais, com as inerentes consequências nos modelos de governação do risco e respetivos sistemas de proteção civil.

- Por último, na formulação cultural e simbólica do risco em Douglas (1992, 2007), a consideração do risco enquanto conceito político na sua relação com os processos de ordem e coesão social, bem como no contributo dos quatro tipos de controlo social da Teoria Cultural, remete para uma tradução dos sistemas políticos dos três países com reflexos nos modelos de governação do risco.

\section{Proposta teórica analítica - Modelos de governação do risco}

O desenvolvimento da proposta teórico-analítica dos modelos tipológicos de governação do risco constituiu-se como quadro de referência central da pesquisa, permitindo a sua modelação enquadrar a pesquisa, delimitar o respetivo campo de ação teórico e, ao mesmo tempo, orientar e monitorizar o trabalho empírico realizado.

Assentando na articulação de cinco grandes dimensões - política, cidadania, participação pública, conceito de desastre e modelos de gestão operacional - promoveu-se, através da decomposição das variáveis e dos indicadores específicos de relevância operativa selecionados, uma análise onde se constroem quatro modelos ideal-típicos de governação do risco.

Sinteticamente refira-se que, em relação à dimensão do domínio político, a análise centrou-se numa leitura dos mandatos intergovernamentais, verificáveis através das relações entre as administrações de grau superior (a central), intermédias (regional, departamental e distrital, consoante os casos) e, por último, locais (autarquias), tipificando-os entre sistemas centralistas, reguladores ou autónomos.

Assim, os centralistas permitem reconhecer os sistemas e culturas políticas mais verticalizadas e prescritivas, identificando-os como regimes onde a autoridade da administração central é diretiva, e até coerciva, relativamente aos restantes escalões intergovernamentais.

Nos sistemas reguladores, considerou-se uma dupla orientação, espelhando mecanismos onde a governação pode assumir um cunho mais vertical ou mais horizontal. No primeiro caso, prevalecem componentes prescritivas ou hierarquizadas que, contudo, são mediadas por uma distribuição de competências e atribuições específicas nos escalões intergovernamentais subsidiários. No segundo caso, de regulação horizontal, regista-se uma maior liberdade institucional, evidenciando-se também maior autonomia por 
parte das administrações intermédias e locais face à central. Essa regulação, no entanto, encontra-se confinada internamente às respetivas estruturas técnicas e funcionais de onde emanam, com pouca - ou nenhuma - articulação com a sociedade civil.

Por último, os sistemas autónomos podem ser definidos pelos mecanismos de independência entre os diferentes níveis intergovernamentais. O escalão central assume um papel de suporte e apoio às medidas dos restantes níveis, garantindo a indispensável coesão política e unidade nacional dessas medidas. Prevalecem relações colaborativas, sendo as orientações emanadas centralmente, mas a definição dos processos e concretização dos projetos e programas são de incumbência dos níveis inferiores.

Os direitos de cidadania são outra importante dimensão analítica de suporte à modelação da governação do risco. Confrontam-se nesta análise os mecanismos que permitem traduzir se se está em presença de uma cidadania inclusiva ou, pelo contrário, exclusiva. Partindo-se do pressuposto de que a cidadania se afirma no princípio do "direito a ter direitos" (Somers, 2008), promove-se uma leitura onde se podem identificar, num jogo de contrários, as situações onde, por um lado, os direitos apenas existem enquanto bens transacionáveis (ou seja, direitos contratualizados em lógicas de oferta e procura no mercado) e, por outro, direitos de liberdade, igualdade e pertença social, representativos de uma cidadania inclusiva, consagrando-os de facto e de jure.

Paralela e subsidiariamente, jogam-se, como não poderia deixar de acontecer, as situações híbridas onde, embora prevalecendo numa formulação de jure, os direitos de cidadania podem ser direcionados, quer para um entendimento enquanto bens públicos, quer como direitos individuais, próximos de lógicas de direitos humanos e menos de pertença social.

A dimensão da participação pública, em forte sintonia com a anterior, centra-se na análise dos fluxos comunicacionais e do envolvimento das populações no sistema de proteção civil. Partindo da tipologia de Rowe e Frewer (2005), onde se distingue a comunicação, a consulta e a participação como vetores distintos das práticas institucionais e das representações sociais (que definem a relação do Estado com os cidadãos), hierarquiza-se a análise, modelando a sua distribuição em diferentes combinações. Assim, e em relação à comunicação, esta reflete uma transmissão unidirecional, top-down, em que as populações se apresentam como destinatários passivos das informações e das decisões, refletindo lógicas verticalizadas. No oposto, a participação, privilegiando correntes bidirecionais, pauta-se por processos onde se enfatizam os mecanismos bottom-up, de relacionamentos, propostas e decisões mais partilhadas entre os emissores e os destinatários. 
Os processos de consulta representam situações mais ambivalentes onde, em função das agregações verificadas - mais comunicação ou mais participação -, permitem deslocar a análise e a modelação tipológica para horizontes mais descentralizados ou mais hierarquizados.

O modo como o conceito de desastre é definido permite evidenciar a orientação prevalecente do modelo de governação do risco existente na sociedade e, por inerência, no respetivo sistema de proteção civil. Nesta formulação consideram-se três conceções que também se apresentam em distintas combinações. Em primeiro lugar, surgem as correntes que interpretam os desastres como o resultado da ação de agentes externos, fora dos sistemas sociais onde se produzem. Próximos, por analogia, das assunções militares e militarizadas sobre as situações de guerra, também aqui os desastres são encarados como um inimigo que vem colocar em causa a estabilidade e ordem social. O foco direciona-se, portanto, para uma aferição dos desastres como fatalidades incontroláveis, e não para os processos de articulação entre a sociedade e o ambiente construído (Quarantelli, 1998). Em segundo lugar, e traduzindo uma visão híbrida da origem dos desastres - combinando fatores externos e internos -, a consideração assenta em mecanismos de incerteza associados a estes fenómenos. Entendidos como acontecimentos incontroláveis e inopinados, a organização e a ação centra-se na capacidade da sociedade em absorver, adaptar-se e recuperar dos impactos sofridos, mantendo o funcionamento da vida social. Mais do que olhar para as causas, a atenção centra-se na construção de mecanismos de resiliência dos sistemas sociais. Em terceiro lugar, e reportando os desastres como fenómenos intrinsecamente sociais, encontra-se uma leitura com ênfase nas vulnerabilidades dos sistemas. O conceito de vulnerabilidade aparece como elemento que, por um lado, define o grau de exposição e da capacidade de resposta existente e, por outro, exprime as (in)aptidões políticas, técnicas e sociais para lidar com os desastres como fenómenos não rotineiros.

A última dimensão considerada, referente aos modelos de gestão operacional, tem ligações umbilicais com a anterior. Confrontam-se aqui duas modelações que, conforme salientado por Dynes (1994), traduzem quadros de referência distintos, pois os pressupostos de partida são, também eles, diferentes. Por um lado, os modelos definidos como de comando e controlo e, por outro, os designados como de resolução de problemas ou de coordenação.

O modelo de comando e controlo é o que maior relevância universal apresenta. Os desastres são entendidos como se de um ataque inimigo se tratasse, alterando, de forma radical, a ordem e funcionamento da sociedade. Neste contexto, subsume-se que as populações civis ficam indefesas, 
expostas e desorganizadas, necessitando de uma autoridade forte no controlo da situação verificada, que encontra maior representatividade e suporte nas instituições militares e militarizadas. Como salienta Dynes (1994: 142; tradução do autor, ênfase no original),

Por conveniência, o modelo dominante é aqui descrito como modelo 'militar' de planeamento de emergência para referir as suas raízes primárias. As premissas fundamentais podem ser entendidas em termos de um "triplo 'C'”. O primeiro 'C' aponta para assunção de que uma emergência se carateriza pelo CAOS e os outros dois ‘Cs' sugerem que o caos só pode ser eliminado por COMANDO e CONTROLO.

No segundo caso, respeitante ao modelo de resolução de problemas, prevalece a assunção de que os desastres não são acontecimentos fora do social. Pelo contrário, é dentro das sociedades que se produzem as condições que potenciam os riscos e os próprios desastres. Por analogia com o anterior modelo, também o de resolução de problemas pode ser caraterizado pelo triplo C, sustentado na Continuidade, Coordenação e Cooperação, refletor de uma maior envolvência e participação social na forma de lidar com os desastres.

Em abono de uma mais concreta observação da realidade, saliente-se que, também nesta dimensão analítica, se podem registar, e registam-se, situações mistas envolvendo os dois modelos. Consoante determinados enquadramentos, podem ser constatadas situações que, misturando parâmetros de ambos os modelos, prevalecem, nuns casos, mais de comando e controlo e, em outros, de resolução de problemas.

Apresenta-se, no Quadro 1, a matriz identificativa dos quatro modelos preponderantes de governação do risco: diretivo, hierárquico, descentralizado e cooperativo.

Numa breve explanação da respetiva estrutura, salientam-se, para todos os domínios, as dimensões que definem a tipologia dos modelos de governação:

- No domínio político cruzam-se os processos oscilando entre padrões mais centralistas, de cunho vertical e prescritivo e os de autonomia, de relações mais colaborativas e cooperativas, considerando-se nos restantes quadrantes as situações intermédias, ou seja, de regulação vertical, num caso, e de regulação horizontal, no outro;

- No domínio da cidadania, observam-se as situações onde os direitos podem ser definidos como contratualizados em oposição aos de índole mais inclusiva, reservando-se os quadrantes dois e três para situações intermédias e híbridas, com os direitos de jure, oscilando entre direitos públicos e bens individuais; 
QUADRO 1 - Tipologias de governação do risco

\begin{tabular}{|c|c|c|c|c|c|}
\hline \multicolumn{6}{|c|}{ PADRÃO POLÍTICO } \\
\hline & & COERCIVO & COOPERATIVO & & \\
\hline \multirow{9}{*}{ 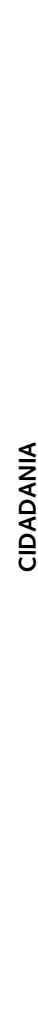 } & \multirow{5}{*}{ 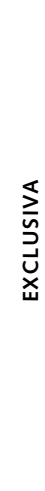 } & MODELO DIRETIVO & MODELO DESCENTRALIZADO & \multirow{5}{*}{ 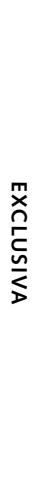 } & \multirow{9}{*}{$\begin{array}{l}\frac{0}{\delta} \\
\frac{2}{2} \\
\frac{2}{2}\end{array}$} \\
\hline & & $\begin{array}{c}\text { Políticas: } \\
\text { centralizadas, verticais } \\
\text { e prescritivas; }\end{array}$ & $\begin{array}{c}\text { Políticas: } \\
\text { regulação horizontal, } \\
\text { coordenação e monitorização; }\end{array}$ & & \\
\hline & & $\begin{array}{c}\text { Cidadania: } \\
\text { direitos contratualizados, exclusão; } \\
\text { Envolvimento público: } \\
\text { comunicação (top-down); }\end{array}$ & $\begin{array}{c}\text { Cidadania: } \\
\text { direitos de jure (bens individuais); } \\
\text { Envolvimento público: } \\
\text { consulta e comunicação; }\end{array}$ & & \\
\hline & & $\begin{array}{l}\text { Conceito de desastre: } \\
\text { agente externo; }\end{array}$ & $\begin{array}{c}\text { Conceito de desastre: } \\
\text { agente externo, vulnerabilidade; }\end{array}$ & & \\
\hline & & $\begin{array}{l}\text { Modelos de } \\
\text { gestão operacional: } \\
\text { comando e controlo. }\end{array}$ & $\begin{array}{c}\text { Modelos de } \\
\text { gestão operacional: } \\
\text { coordenação e comando e controlo. }\end{array}$ & & \\
\hline & \multirow{4}{*}{ 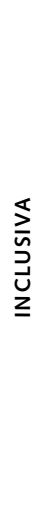 } & $\begin{array}{l}\text { MODELO HIERÁRQUICO } \\
\text { Políticas: } \\
\text { reguladoras, hierarquizadas } \\
\text { e verticais; }\end{array}$ & $\begin{array}{c}\text { MODELO COOPERATIVO } \\
\text { Políticas: } \\
\text { descentralizadas, colaborativas } \\
\text { e autónomas; }\end{array}$ & \multirow{4}{*}{ 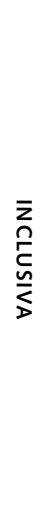 } & \\
\hline & & $\begin{array}{l}\text { Cidadania: } \\
\text { direitos de jure } \\
\text { (bens públicos); } \\
\text { Envolvimento público: } \\
\text { consulta e participação; }\end{array}$ & $\begin{array}{l}\text { Cidadania: } \\
\text { direitos de jure e de facto, } \\
\text { inclusão social; } \\
\text { Envolvimento público: } \\
\text { participação; }\end{array}$ & & \\
\hline & & $\begin{array}{l}\text { Conceito de desastre: } \\
\text { agente externo, incerteza; }\end{array}$ & $\begin{array}{l}\text { Conceito de desastre: } \\
\text { incerteza, vulnerabilidade; }\end{array}$ & & \\
\hline & & $\begin{array}{c}\text { Modelos de } \\
\text { gestão operacional: } \\
\text { comando e controlo e coordenação. }\end{array}$ & $\begin{array}{l}\text { Modelos de } \\
\text { gestão operacional: } \\
\text { coordenação. }\end{array}$ & & \\
\hline & & COERCIVO & COOPERATIVO & & \\
\hline
\end{tabular}

Fonte: elaboração do autor.

- No domínio do envolvimento e participação pública distinguem-se os processos onde prevalecem lógicas top-down de comunicação dos de cariz participativo mais bottom-up, com inerentes variações nos outros quadrantes da matriz, onde a consulta pública predomina como norma, variando entre processos de participação e comunicação;

- O conceito de desastre gravita em torno de entendimentos que o consideram enquanto agente externo, com formulações mais posicionadas dentro de uma origem social, verificando-se modelações combinatórias entre essas duas conceções nos restantes quadrantes, associadas, num 
caso, a variações posicionadas na incerteza e, no outro, a considerações de vulnerabilidade;

- Por último, e em relação aos modelos de gestão operacional, confrontam-se aqui visões de cunho mais militarizado de comando e controlo, com outras onde prevalece uma lógica mais de coordenação e cooperação, ficando os outros quadrantes com as combinações híbridas entre comando e controlo e cooperação.

Definidos numa lógica de tipos-ideais, os quatro modelos que daqui resultam, modelos diretivo, hierárquico, descentralizado e cooperativo, constituem-se com uma verdadeira matriz explicativa de suporte ao conhecimento da organização e do funcionamento dos sistemas de proteção civil.

A virtude desta modelação é possibilitar uma leitura analítica e interpretativa das diferenças e das semelhanças que se produzem, quer numa contextualização interna dos sistemas de proteção civil de cada país, quer na comparabilidade entre sistemas de diferentes países. Tanto num caso como no outro, esta referenciação aplica-se quer ao nível da sua evolução histórica, quer em relação à conjuntura atual.

Como se depreende da leitura comparativa em relação às tipologias de governação do risco, não se trata de encontrar modelos analiticamente fechados e absolutos. Embora a elaboração teórica assente em parâmetros definidos e devidamente enquadrados concetual e metodologicamente - como resultado indispensável para uma pertinência explicativa e interpretativa - os modelos construídos, quando em confronto com a realidade, caraterizam-se por formulações e articulações híbridas entre eles.

\section{Análise comparativa no estudo de casos: metodologia e resultados}

Relativamente à metodologia de suporte à investigação, optou-se por uma pesquisa centrada no estudo de caso, assente na análise comparativa dos sistemas dos três países considerados. A escolha do estudo de caso, dentro da linha definida por Yin (2003), assentou numa perspetiva de obtenção de uma visão global do processo investigativo, com integração das componentes de exploração, descrição e explicação como condição indispensável a um tratamento sistémico e holístico dos resultados, e pela opção do que alguns autores definem como demonstração paralela dentro de um ciclo de investigação. Permitiu-se, assim, evidenciar, de forma diacrónica e sincrónica, as semelhanças/diferenças e as analogias/distinções entre os três sistemas, permitindo-se perceber os "comos" e os "porquês" da forma como se constituíram e desenvolveram os respetivos modelos de governação do risco. Esta ferramenta metodológica constituiu um excelente instrumento operativo para a análise dos casos de estudo, evidenciando a comparabilidade 
quer interna, nos próprios domínios e indicadores operativos dentro de cada realidade, quer externa, nas referidas diferenças e semelhanças entre cada sistema.

Em relação aos resultados alcançados, salientam-se as seguintes conclusões: as decorrentes da pesquisa empírica e as relacionadas com a aplicação do modelo tipológico de governação do risco.

Assim, e relativamente aos resultados da investigação empírica, salienta-se que os três países dispõem de sistemas de proteção civil com finalidades e objetivos de segurança semelhantes. Contudo, e como se pode observar no Quadro 2, apesar dessas conformidades, apresentam modelações estratégicas e operacionais distintas, com uma matriz mais security no caso britânico, um sistema quase exclusivo na área do safety em Portugal, e um modelo híbrido com as duas componentes na situação de França.

QUADRO 2 - Caraterísticas dos três sistemas nacionais

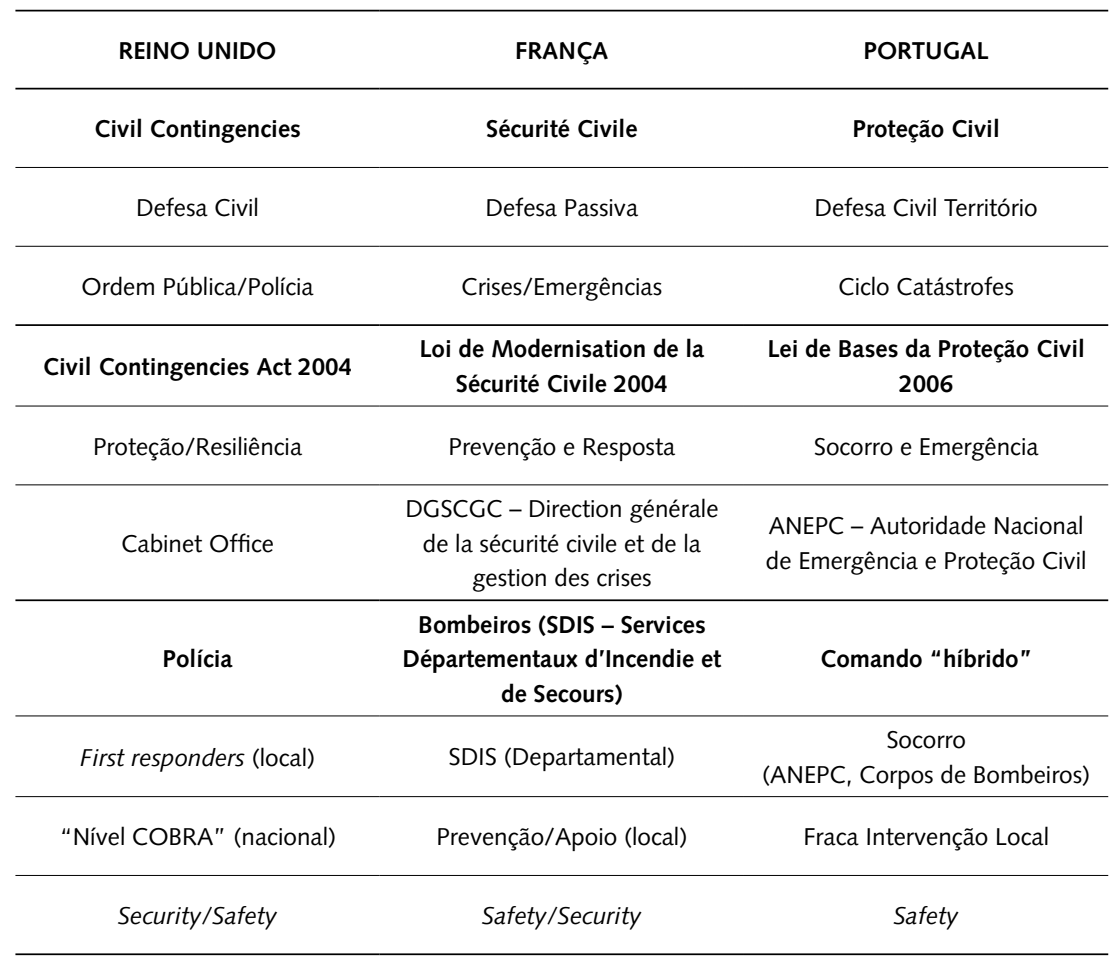

Fonte: elaboração do autor. 
Com pequenas variações, todos eles têm as suas raízes nas organizações de defesa civil que emergiram no período entre as duas guerras mundiais e se foram sedimentando durante a Segunda Guerra Mundial. Contudo, e decorrente dos contextos históricos, sociopolíticos e culturais dos países, constata-se a existência de especificidades e particularidades em cada um dos casos. Como referido anteriormente na formulação da primeira hipótese de investigação, os sistemas são influenciados, quer pela cultura política do país, quer pela história dos acontecimentos catastróficos neles registados. Estas condições foram decisivas na evolução da organização e funcionamento dos três sistemas de proteção civil.

\subsection{Análise do sistema britânico}

Numa análise mais particularizada a cada um dos países, e começando pelo Reino Unido, salienta-se, como se referiu, que o sistema britânico se carateriza por uma componente de domínio security, refletindo uma visão estratégica fortemente centrada na ordem pública. Esta orientação encontra as suas raízes e justificação oficial em acontecimentos marcantes, que foram sendo registados na sua história recente, nomeadamente com situações de motins, greves, terrorismo, guerras, entre muitos outros. Refira-se, a título de exemplo, que um dos diplomas jurídicos que estão na base do sistema de segurança britânico, o Emergency Powers Act de 1920 foi, de forma manifesta, concebido como reação e resposta às greves dos trabalhadores dos setores mineiro e dos transportes, em outubro desse ano. Todo um contexto que, entre outros fatores, contribui para explicar a preponderância da polícia no sistema, enquanto entidade de comando e coordenação, sendo também essa autoridade, simultaneamente, extensível à gestão dos acidentes e desastres com origem natural e tecnológica, ou seja, de acontecimentos com prevalência na área do safety.

Com o fim da Guerra Fria, e durante a transição do milénio, ainda foram observadas algumas tentativas de reformar o sistema, aliviando a matriz securitária. Contudo, por razões que vão desde a falta de vontade política e o excesso de burocracia dos serviços administrativos do Whitehall (Norman e Coles, 2002), passam pelas inundações, a crise de combustíveis do ano 2000 e o risco associado à febre aftosa, e culminam nos acontecimentos do 11 de Setembro, nunca essa reestruturação legislativa se veio a verificar. Também as constantes ameaças do Sein Fein e do seu braço armado IRA e, posteriormente, os ataques e atentados da $\mathrm{Al}$ Qaeda e do ISIS, vieram a contribuir decisivamente para a manutenção, e reforço, da componente securitária e policial do sistema.

O Civil Contingencies Act (CCA) de 2004, vem clarificar as duas áreas principais de intervenção do sistema britânico: a civil defense, na segurança 
das populações civis em relação às ameaças de guerra e o terrorismo, e a emergency planning, na proteção dos cidadãos contra emergências e acidentes naturais e tecnológicos (Cabinet Office, 2004).

Traduz-se, assim, em relação ao sistema, um entendimento mais centrado na resiliência da nação, para a qual a própria designação de Civil Contingencies não pode ser observada de uma forma meramente arbitrária e casual. As emergências são encaradas em relação às suas consequências e menos face às suas causas, numa assunção de que os eventos, quaisquer que sejam, se pautam por caraterísticas de incerteza. Prevalece, pois, um entendimento estratégico e organizacional, mais direcionado para a proteção das populações, em contraponto com as habituais correntes de gestão de emergência, mais focadas nas estruturas operacionais de resposta.

Relativamente à atribuição das competências pelos vários escalões governamentais, o sistema britânico privilegia o nível local como o primeiro estádio de intervenção e resposta, através das respetivas autoridades locais. Aqui se incluem os first responders (bombeiros, polícia, etc.) e os serviços de emergência, reforçados, sempre que necessário, pelos second responders (serviços sociais, empresas de infraestruturas, etc.). O comando e coordenação é das forças policiais respetivas em cada jurisdição. Os escalões superiores - regional e, sobretudo, o nacional - intervêm quando a situação, pela sua dimensão e impacto, se justifica, exigindo a assunção da coordenação e direção das operações pelo nível central. Neste nível, as respostas encontram-se hierarquizadas em três graus de importância, só se ativando, contudo, o designado Gabinete COBRA (Cabinet Office Briefing Room A) para situações de importância dois e três, onde se incluem emergências de cariz abrangente e prolongado (pandemias, determinadas ameaças e ataques terroristas), e acontecimentos catastróficos de grande dimensão, como foram os casos do acidente de Chernobyl e os ataques do 11 de Setembro de 2001 que, mesmo sendo fora do Reino Unido, implicaram o seu acompanhamento ao mais alto nível. Apesar da verticalidade prescritiva das orientações legais do governo de Sua Majestade sobre os escalões inferiores da administração, constata-se que a mesma obedece a lógicas mais de regulação horizontal, como pode ser atestado pela atribuição de competências operacionais ao nível local.

Relativamente ao envolvimento das populações no sistema, as mesmas são encaradas mais numa lógica de destinatários dos processos do que sujeitos do mesmo. A segurança é considerada como um valor nacional, para o qual todos devem contribuir com os seus comportamentos e formas de estar. Contudo, os direitos dos cidadãos são vistos, sobretudo, como direitos individuais. O próprio CCA de 2014, referindo-se às populações, alude à designação de "o público", numa lógica mais de recetores das 
medidas tomadas pela administração pública do que numa ótica inclusiva de participação nas mesmas.

\subsection{Análise do sistema francês}

O sistema de proteção civil francês, que adota atualmente a designação de Sécurité civile, foi evoluindo gradualmente, acompanhando e adaptando-se aos respetivos contextos históricos, políticos e sociais pelos quais a França foi passando até aos dias de hoje. Conforme sintetiza Mariani (2004: 14; tradução do autor),

A evolução das missões ligadas à proteção das populações contra as calamidades públicas traduziu-se, ao longo do tempo, por uma sucessão de conceitos ligados a diferentes realidades: à defesa passiva definida em 1935 e confiada ao Ministério da Defesa sucede, em 1944, a proteção civil transferida para o Ministério do Interior e formalizada em 1951 pela criação do serviço nacional de proteção civil. A disposição regulamentar de 7 de janeiro de 1959 dá origem à doutrina da defesa civil dentro de um contexto de desenvolvimento de uma política de dissuasão, enquanto que em 1975 se criará a direção da segurança civil, dentro do quadro de um novo conceito de "segurança civil", específico à França.

Refletindo um quadro idiossincrático próprio, a designação de sécurité civile apresenta-se nas representações sociais francesas, como um conceito sistematizador e abrangente das várias áreas de segurança e proteção das populações. De qualquer modo, embora prevaleça um cunho de âmbito safety na organização e funcionamento do sistema, a situação tem vindo a caminhar para lógicas de incorporação das vertentes securitárias (security), a que não são estranhos os acontecimentos verificados na sociedade francesa, com particular relevância para os atentados terroristas.

O sistema francês assenta fortemente no papel dos corpos de bombeiros sapadores como estrutura de comando e de intervenção operacional nas situações de acidentes, crises e catástrofes. A situação foi evoluindo gradualmente em torno de uma profissionalização do sistema de socorro, embora continuem a coabitar corpos de bombeiros voluntários com profissionais. Nos anos subsequentes ao pós-guerra, e até à década de 90 do século xx, o sistema encontrava-se genericamente suportado pelos municípios e respetivos presidentes de câmara. A autoridade encontrava-se neles delegada. Contudo, a constatação das dificuldades por parte de determinadas communes em lidar com as crises e emergências, evidenciando diferentes graus de preparação e resposta aos acidentes com implicações em danos e vítimas, conduziu o governo a legislar no sentido de centralizar as ações de 
resposta a nível departamental, de forma que todos os cidadãos pudessem ser destinatários, por igual, do socorro quando necessário. A designada Lei da Departamentalização de 1996 formaliza a transferência da gestão dos sapadores bombeiros, institucionalizando, profissionalizando e reforçando o comando dos Serviços Departamentais de Incêndio e Socorro (SDIS). Apenas as cidades de Paris e Marselha se mantêm autónomas com corpos de bombeiros de cunho militarizado.

A autoridade central do sistema francês está cometida à Direction générale de la sécurité civile et de la gestion des crises (DGSCGC), sob a tutela do Ministro do Interior, tendo como matriz jurídica a Loi de modernisation de la sécurité civile de 2004 que considera a segurança nas suas vertentes coletivas e individuais. A componente operacional reside nos já referidos SDIS, podendo ser reforçados com meios do Estado sempre que a situação o exija, nomeadamente com as forças de segurança e os meios militares - como foi o caso nos ataques terroristas perpetuados em Paris, Nice e outras localidades francesas mais recentemente. Existe uma hierarquia de ativação dos planos, salientando-se a este propósito os Planos ORSEC - acrónimo de Organisation de la Réponse de Sécurité Civile -, cuja matriz de acionamento se encontra posicionada nos níveis territoriais intermédios do próprio Estado. As competências e responsabilidades dos municípios estão direcionadas mais para as ações de prevenção, sensibilização e planeamento, assumindo, no apoio às emergências, missões sobretudo de suporte aos desalojados e ao posterior restabelecimento da normalidade pós-emergência. São, no entanto, obrigados, em termos de planeamento a dispor de um Plan communal de sauvegarde, definido, na sua estrutura e conteúdo, segundo orientações da administração central.

O envolvimento das populações no sistema é marcado por alguma ambiguidade. Por um lado, referencia-se a importância da sua participação na própria Loi de modernisation de la sécurité civile, afirmando-se que "Qualquer pessoa contribui através do seu comportamento para a segurança civil". ${ }^{1}$ Por outro, contudo, constata-se que continuarem a ser as funções e atribuições do sistema um território muito específico dos agentes formais e institucionais da segurança civil.

De qualquer modo, saliente-se a preocupação existente com estas matérias na sociedade francesa, contemplando-se nos curricula escolares programas formativos na área da informação, sensibilização e preparação em prol de uma cultura de segurança.

\footnotetext{
${ }^{1}$ Loi 2004-811 du 13 août 2004 de modernisation de la sécurité civile. Consultado a 22.07.2016, em www.legifrance.gouv.fr. Tradução do autor.
} 


\subsection{Análise do sistema português}

Por último, e em relação a Portugal, saliente-se que as primeiras referências ao sistema remontam ao ano de 1942, com a criação da Defesa Civil do Território (DCT), na Legião Portuguesa, sob a tutela do Ministério da Guerra. Refletindo as preocupações da época, é definido no articulado do Decreto Lei n. ${ }^{\circ} 31956$ que incumbia à DCT "assegurar o regular funcionamento, em tempo de guerra ou de grave emergência, das actividades nacionais, interessa[ndo] a toda a população e à conservação da riqueza pública".

De cunho intrinsecamente militar, a DCT viria a ter a sua consagração jurídica em 1958, com a publicação da Lei n. ${ }^{\circ} 2093$, de 20 de junho. A direção do sistema continuava cometida ao Ministro da Defesa Nacional afirmando-se que competia à Legião Portuguesa "a preparação, organização e execução da defesa civil, integrada no plano geral da defesa militar e civil, [...] que para o efeito se encarregará da Organização Nacional da Defesa Civil do Território". ${ }^{3}$ De comando militar, o sistema incorpora lógicas comuns relacionadas, quer com a segurança interna, quer com a proteção civil, quer, ainda, com a própria defesa nacional. A Organização Nacional de Defesa Civil do Território manter-se-á até ao dia 25 de abril de 1974, sendo nessa data extinta.

Somente em 1975 foi criado o Serviço Nacional de Proteção Civil (SNPC) que, no entanto, continuou a ser dirigido por elementos oriundos das forças armadas, ficando sob a tutela do Ministério da Defesa. De qualquer modo, o âmbito da sua ação transferiu-se, genericamente, para o domínio do safety. Com a publicação da Lei de Defesa Nacional e das Forças Armadas, em 1982, o SNPC transitou para a alçada da Presidência do Conselho de Ministros e, posteriormente, para o Ministério da Administração Interna (MAI), onde se mantém atualmente. Até aos primeiros anos do século XXI, o sistema de proteção civil encontrava-se dividido entre uma estrutura de coordenação, assegurada pelo SNPC e uma outra operacional, da responsabilidade do Serviço Nacional de Bombeiros, ambos no MAI. A fusão dos dois serviços, à qual se juntou a Comissão Nacional Especializada de Fogos Florestais, aconteceu em 2003 com a criação do Serviço Nacional de Bombeiros e Proteção Civil, sendo que em 2007, passou a ser designada por Autoridade Nacional de Proteção Civil (ANPC) e, em 2019, por Autoridade Nacional de Emergência e Proteção Civil (ANEPC).

Como se referiu, prevalece no sistema português uma lógica intrinsecamente safety, atestada quer pela primeira Lei de Bases de 1991 quer pelo

\footnotetext{
${ }^{2}$ Decreto Lei n. ${ }^{\circ}$ 31956, de 2 de abril de 1942, Diário do Governo n. ${ }^{\circ}$ 76/1942, Série I. Lisboa: Ministério da Guerra. Consultado a 08.10.2016, em https://dre.pt/application/file/166550.

${ }^{3}$ Lei n. ${ }^{\circ} 2093$, de 20 de julho de 1958, Diário do Governo n. ${ }^{\circ}$ 131/1958, Série I, Presidência da República, Lisboa. Consultado a 14.05.2016, em https://dre.pt/application/file/353454.
} 
atual diploma que revogou o anterior, a Lei n. ${ }^{\circ} 26 / 2007$, republicada pela Lei n. ${ }^{\circ} 80 / 2015 .{ }^{4}$ Nas suas componentes operacionais, o sistema nacional continua a suportar-se nos corpos de bombeiros que, como é sabido, se encontram distribuídos por profissionais, mistos e voluntários. Saliente-se que os corpos de bombeiros voluntários pertencem a associações de direito privado, as Associações Humanitários de Bombeiros Voluntários, detentoras, na sua esmagadora maioria, do estatuto de utilidade pública.

As representações sociais prevalecentes na opinião pública portuguesa consideram os corpos de bombeiros como o principal agente de proteção civil do sistema. Contudo, e mais recentemente, a Guarda Nacional Republicana (GNR), através do Grupo de Intervenção de Proteção e Socorro, tem vindo a afirmar-se neste domínio. Poderá aqui estar a configurar-se uma evolução na matriz do sistema, progredindo de uma lógica intrinsecamente safety para uma situação híbrida contemplando também o security.

No que reporta ao envolvimento das populações no sistema, constata-se uma ambivalência notória. Se discursivamente prevalece a ideia de que somos todos proteção civil, já a legislação e, sobretudo, a prática operativa muito centrada em peritos tendem a relegar os cidadãos para destinatários das políticas e medidas do sistema, pouco apostando na sua contribuição. A este propósito é bem elucidativa a constatação de Mendes (2017) sobre a fraca ou nula participação das populações nas ações do sistema de proteção civil quando, em artigo de opinião e a propósito dos incêndios de 2017 em Pedrógão Grande e na Região Centro, afirmou que,

a consequência maior dos grandes incêndios de junho e de outubro em Portugal foi a confirmação por todos e por todas da sua vulnerabilidade perante acontecimentos extremos, num país pautado por lógicas de planeamento e de proteção civil burocráticas e totalmente assentes nas projeções dos peritos e sem participação direta dos interessados.

\subsection{Análise comparativa dos sistemas britânico, francês e português}

Como nota conclusiva dos resultados empíricos, saliente-se que os sistemas britânico e francês têm evoluído numa lógica de integração das componentes security e safety, com incidência especial para o britânico. Já o sistema português continua a privilegiar a vertente safety, embora a entrada em cena da GNR possa vir a constituir um indício da integração da vertente security.

\footnotetext{
${ }^{4}$ Lei n. ${ }^{\circ}$ 80/2015 de 3 de agosto de 2015, Diário da República n. ${ }^{\circ}$ 149/2015, Série I (Segunda alteração à Lei n. ${ }^{\circ}$ 27/2006, de 3 de julho, que aprova a Lei de Bases da Proteção Civil). Lisboa: Assembleia da República. Consultado a 29.09.2017, em http://data.dre.pt/eli/lei/80/2015/08/03/p/ dre/pt/html.
} 
QUADRO 3 - Aplicação do modelo tipológico de governação do risco

\begin{tabular}{|c|c|c|c|}
\hline & REINO UNIDO & FRANÇA & PORTUGAL \\
\hline $\begin{array}{l}\text { Padrão } \\
\text { político }\end{array}$ & $\begin{array}{c}\text { Hierárquicos / } \\
\text { Descentralizados }\end{array}$ & $\begin{array}{c}\text { Descentralizados / } \\
\text { Hierárquicos }\end{array}$ & $\begin{array}{c}\text { Hierárquicos / } \\
\text { Descentralizados }\end{array}$ \\
\hline Cidadania & $\begin{array}{c}\text { Hierárquicos / } \\
\text { Descentralizados }\end{array}$ & $\begin{array}{c}\text { Hierárquicos / } \\
\text { Descentralizados }\end{array}$ & Hierárquicos \\
\hline $\begin{array}{l}\text { Envolvimento } \\
\text { público }\end{array}$ & $\begin{array}{c}\text { Hierárquicos / } \\
\text { Descentralizados }\end{array}$ & $\begin{array}{c}\text { Descentralizados / } \\
\text { Cooperativos / } \\
\text { Hierárquicos }\end{array}$ & $\begin{array}{c}\text { Hierárquicos / } \\
\text { Descentralizados }\end{array}$ \\
\hline $\begin{array}{l}\text { Conceito de } \\
\text { desastre }\end{array}$ & $\begin{array}{c}\text { Hierárquicos / } \\
\text { Descentralizados }\end{array}$ & $\begin{array}{c}\text { Descentralizados / } \\
\text { Hierárquicos }\end{array}$ & $\begin{array}{c}\text { Descentralizados / } \\
\text { Hierárquicos / } \\
\text { Cooperativos }\end{array}$ \\
\hline \multirow[t]{2}{*}{$\begin{array}{l}\text { Modelo de gestão } \\
\text { operacional }\end{array}$} & $\begin{array}{c}\text { Hierárquicos / } \\
\text { Descentralizados }\end{array}$ & $\begin{array}{c}\text { Descentralizados / } \\
\text { Hierárquicos }\end{array}$ & Hierárquicos \\
\hline & $\begin{array}{c}\text { Hierárquico / } \\
\text { Descentralizado }\end{array}$ & $\begin{array}{c}\text { Descentralizado / } \\
\text { Hierárquico }\end{array}$ & $\begin{array}{c}\text { Hierárquico / } \\
\text { Descentralizado }\end{array}$ \\
\hline
\end{tabular}

Fonte: elaborado pelo autor.

O Quadro 3 sintetiza os resultados da aplicação do modelo tipológico de governação do risco aos três países. Evidencia-se, numa leitura comparativa global dos três sistemas, uma analogia entre os sistemas britânico e português, com prevalência de um modelo hierárquico, com composição subsidiária do modelo descentralizado, enquanto o sistema francês, pelo contrário, é pautado por um modelo mais descentralizado, embora com registos também próximos do modelo hierárquico.

O sistema britânico carateriza-se, no padrão político, por uma articulação entre os modelos hierárquico e descentralizado. Concentrada no nível superior da administração do Estado, as políticas, legislação e orientações prefiguram mecanismos de índole prescritiva e vertical. Já ao nível das relações intergovernamentais, especificamente no sistema de organização da resposta de emergência, embora determinadas superiormente, a responsabilidade da ação reside nos first responders e nas local authorities, subentendendo lógicas mais de regulação horizontal.

$\mathrm{Na}$ mesma linha, no que se refere à dimensão política, o sistema francês inverte ligeiramente a lógica do seu congénere britânico. Caraterizado, inicialmente, por uma modelação mais descentralizada de regulação horizontal, começou, sobretudo nos finais do século Xx, a apresentar lógicas hierarquizadas mais verticalizadas, por efeito da transferência de poderes e responsabilidades para os escalões intermédios do Estado, designadamente nos départements (departamentos) e respetivos SDIS. 
A evolução do sistema português traduz o processo de transição histórico verificado no país. Assente num sistema intrinsecamente diretivo, resultado do regime político ditatorial que prevaleceu até ao 25 de Abril, veio a caminhar para lógicas de regulação de cunho hierárquico, mas onde se podem constatar alguns registos mais descentralizados. A matriz preponderante do modelo é, indubitavelmente, de cunho vertical nos processos de regulação, embora tenha vindo a emanar um maior envolvimento local nas ações, pressupondo formulações colaborativas próximas de uma regulação horizontal.

Em síntese, e no que se refere ao padrão político, pode salientar-se uma certa homogeneidade do Reino Unido e de Portugal, apresentando modelações hierárquicas com transições descentralizadas, enquanto a França evidencia um modelo descentralizado com manifestações hierárquicas.

No domínio da cidadania, no Reino Unido prevalecem lógicas híbridas, misturando processos mais inclusivos, com situações onde os direitos apresentam caraterísticas mais individualizadas de direitos humanos. Centrado no modelo hierárquico, pode, no entanto, considerar-se oscilar pelo descentralizado se se atender à sua definição de jure nos direitos individuais.

O registo francês é análogo ao britânico. Consagrando nas narrativas oficiais a importância dos cidadãos no sistema, os direitos de cidadania apresentam-se como bens públicos, de jure. Não deixam, no entanto, de estar presentes mecanismos que afirmam a cidadania como valor individual, prefigurando a modelação descentralizada.

Ultrapassando o período ditatorial, onde os direitos eram de exclusão, o sistema português assiste atualmente a processos de maior inclusão das populações na vida pública. Contudo, pese embora as narrativas e discursos oficiais, a cidadania é muito pautada por lógicas definidas como hierárquicas, considerando-se os direitos enquanto valores públicos e coletivos.

Assim, e no domínio da cidadania, quer a França quer o Reino Unido apresentam modelações híbridas idênticas, enquanto Portugal se localiza no modelo hierárquico.

No terceiro domínio, o envolvimento público, o sistema britânico, embora oscilando entre os modelos hierárquico e descentralizado, é mais enfático no primeiro, devido aos processos de consulta pública que são submetidos à discussão sempre que se promovem alterações legislativas. A componente da participação, contudo, apresenta-se mais virtual e retórica do que real.

O sistema francês reúne caraterísticas de três das modelações de tipologias de governação do risco. Prevalecendo a descentralizada, pelos processos de consulta e comunicação - as populações enquanto destinatárias das políticas públicas do sistema nacional -, passa pela cooperativa - envolvimento 
das populações nos domínios da prevenção e da resposta de emergência -, e inclui a hierárquica - apelo que é feito à participação pública no sistema.

Relativamente a Portugal, os processos são muito análogos ao da cidadania. Encarando os cidadãos como recetores e destinatários, prevalecem mecanismos de consulta e comunicação de cariz hierarquizado. Embora formalmente considerando aspetos como a audição pública dos planos, essa circunstância não pode ser entendida, na prática, como uma participação real no sistema, ficando-se pelo nível mais simples da referida consulta e comunicação.

Em relação ao domínio do envolvimento público, o Reino Unido e Portugal apresentam leituras idênticas, prevalecendo o modelo hierárquico seguido do descentralizado como referenciais desta dimensão analítica. Já a França regista um modelo descentralizado mas oscilando, também, entre o cooperativo e o hierárquico.

Passando para o conceito de desastre, o sistema britânico apresenta uma leitura enquanto agente externo - acentuando, contudo, caraterísticas de incerteza que traduzem opções estratégicas mais centradas em políticas de resiliência do sistema. Neste contexto, verifica-se a prevalência do modelo hierárquico, com manifestações, também, do descentralizado.

No sistema francês, a lógica é distinta do britânico. Há um deslocar do conceito de desastre para o das vulnerabilidades, embora se mantenham combinações com acontecimentos enquanto agentes externos. Regista-se uma modelação de cariz mais descentralizado embora incorporando, subsidiariamente, direcionamentos mais hierárquicos.

A situação portuguesa, próxima da francesa, tem vindo contudo a incluir outras representações que direcionam o problema para o âmbito próximo da incerteza e vulnerabilidade. As correntes que tratam os desastres como agentes externos ainda se mantêm, mas novas representações sociais começam a observar a causa dos mesmos dentro do próprio sistema social.

O domínio do conceito de desastre apresenta diferentes representações institucionais pelos três sistemas. Na melhor tradição castrense, ainda se mantêm considerações de agente externo, como é, de forma mais notória, o caso britânico, direcionando-o para modelos entre o hierárquico e o descentralizado. No entanto, essa representatividade também se encontra patente, embora de forma diferenciada, nos sistemas francês e português. Aqui prevalecem lógicas combinatórias entre a incerteza e a vulnerabilidade, com distintos ajustamentos entre elas, repercutindo-se nas tipologias dos modelos considerados. A situação portuguesa - garantida sobretudo através da ação doutrinária da comunidade científica - permite começar a encontrar pontos de contacto com o modelo definido como cooperativo. 
Por último, e no modelo de gestão operacional, o Reino Unido apresenta uma prevalência de comando e controlo, embora, no âmbito do relacionamento intergovernamental se encontrem mecanismos de coordenação, indiciando modelos de cunho hierárquico com variantes de descentralizado.

Em França, por efeito da combinação entre os mecanismos de coordenação a nível da direção, e de comando e controlo no âmbito operacional, o sistema pode ser tipificado como descentralizado. Não deixam, no entanto, de estar presentes indicadores de cariz hierárquico.

Portugal, embora com distintos registos, tem apresentado ao nível das representações e perceções sociais modelações hierárquicas, com o comando e controlo a prevalecer. Contudo, por efeito dos jogos de equilíbrios entre atores e respetivas dinâmicas sociais, emergem mecanismos de coordenação que ainda se apresentam insipientes para alterar o tipo de modelo predominante nesta análise.

Os modelos de gestão operacional acompanham de perto quer a concetualização dos desastres quer o padrão político existente, não podendo ser esquecidos fatores como a própria evolução histórica dos sistemas e os seus atuais contextos sociopolíticos. Assim se pode justificar o cariz hierárquico preponderante do sistema britânico, com contribuições de cunho descentralizado e, pelo contrário, a matriz mais descentralizada do sistema francês com registos também hierárquicos. O sistema português, atendendo ao seu histórico e ao quadro jurídico atual, apresenta uma modelação de raiz hierárquica.

\section{Nota conclusiva}

Confirmando a importância do estudo e conhecimento dos processos de governação do risco, enquanto referenciais explicativos da organização dos Estados na prossecução da segurança, salienta-se, como síntese conclusiva, a indispensabilidade de atender a quatro grandes fatores explicativos na análise dos respetivos sistemas.

- O primeiro resulta da importância em considerar os mecanismos definidores da governação do risco dentro dos contextos políticos onde os mesmos se desenvolvem. Os ambientes políticos e as conjunturas históricas apresentam-se como vetores indispensáveis para uma cabal compreensão dos pressupostos definidores das políticas públicas de segurança e da sua implementação;

- O segundo passa pela relevância em incluir uma abordagem das relações intergovernamentais entre os escalões superiores e os inferiores da administração, enquanto vetores explicativos da estrutura 
e organização dos sistemas. A análise das combinações existentes ao nível dos poderes, lideranças e compromissos entre as administrações do Estado, transpostas, ou não, no quadro jurídico, são um dos vetores essenciais para o conhecimento dos desafios institucionais com repercussões evidentes nos mecanismos de segurança;

- Um terceiro releva do conhecimento das dinâmicas, formais e informais, envolvendo, relacionalmente, os atores sociais da sociedade civil e os stakebolders nos mecanismos institucionais da própria administração pública. Apresentando com frequência um distanciamento entre narrativas e práticas, a forma como se desenvolvem os processos participativos e colaborativos não raramente se traduzem em diferentes modos de encarar a segurança, com consequências óbvias na sua maior ou menor garantia;

- Por fim, a importância de introduzir as distintas representações políticas e sociais que se vão construindo em redor do edifício da segurança e da proteção civil, moldando as orientações e decisões sobre os próprios sistemas. Uma leitura compreensiva da forma como se estruturam os sistemas de segurança tem que, analiticamente, observar as distintas combinações existentes entre as diferentes forças e protagonistas, num jogo marcado por interesses políticos, económicos e sociais, mas também por razões histórico-culturais.

Recuperando a pergunta de partida, onde se questionava qual, ou quais, os modelos de governação do risco que predominam na definição e caraterização dos sistemas de proteção civil, refira-se que a resposta a essa interpelação obriga não apenas a ter de abarcar diferentes territórios epistemológicos, como também a promover leituras transversais no tempo e no espaço, associando nos processos de diacronia e sincronia as respetivas reflexividades causa-efeito. Portanto, e como brevíssima nota final, encontra assim pertinência a identificação de correspondência entre a construção e modelação teórico-analítica e a sua respetiva confrontação empírica, confirmando a matriz desenvolvida, nos seus domínios políticos, de cidadania, de participação pública, de concetualização dos desastres e dos modelos de gestão operacional, como instrumentos fundamentais na explicação dos sistemas de proteção civil e de governação do risco.

\section{Referências bibliográficas}

Aven, Terje; Renn, Ortwin (2010), Risk Management and Governance Concepts, Guidelines and Applications. Berlin: Springer.

Beck, Ulrich (2009), World at Risk. United Kingdom: Polity Press. 
Britton, Neil R. (2007), “National Planning and Response: National Systems”, in Havidán Rodríguez; Enrico L. Quarantelli; Russell R. Dynes (orgs.), Handbook of Disaster Research. New York: Springer, 347-367.

Cabinet Office (2004), "Civil Contingencies Act 2004: A Short Guide (Revised)”, Civil Contingencies Secretariat. Consultado a 22.08.2016, em https://webarchive.national archives.gov.uk/20130129070403/http://www.cabinetoffice.gov.uk/sites/default/ files/resources/ccact-shortguide.pdf.

Douglas, Mary (1992), Risk and Blame: Essays in Cultural Theory. London: Routledge. Douglas, Mary (2007), “A History of Grid and Group Cultural Theory”. Toronto: University of Toronto. Consultado a 22.04.2018, em http://projects.chass.utoronto. ca/semiotics/cyber/douglas1.pdf.

Dynes, Russell (1994), "Community Emergency Planning: False Assumptions and Inappropriate Analogies”, International Journal of Mass Emergencies and Disasters, 12(2), 141-158.

Foucault, Michel (2008), Segurança, território, população. Curso dado no Collège de France (1977-1978). São Paulo: Martins Fontes. Tradução de Eduardo Brandão.

IRGC - International Risk Governance Council (2005), White Paper on Risk Governance: Towards an Integrative Approach. Geneva: International Risk Governance Council. IRGC - International Risk Governance Council (2008), An Introduction to the IRGC Risk Governance Framework. Geneva: International Risk Governance Council.

Mariani, Thierry (2004), "Rapport fait au nom de la Commission des Lois Constitutionnelles, de la Législation et de l'Administration Générale de l'République sur le project de Loi, adopté par le Sénat après Déclaration d'Urgence de modernisation de la sécurité civile, Rapport d'Information n. ${ }^{\circ}$ 1712, Assemblée Nationale, Constitution du 4 Octobre 1958, Douzième Législature. Enregistré à la Présidence de l'Assemblée nationale le 6 juillet 2004". Consultado a 27.08.2015, em http://www. assemblee-nationale.fr/12/pdf/rapports/r1712.pdf.

Mendes, José Manuel (2017), “A vitória de Estado ad hoc e a resistência da sociedade civil”, Jornal Público, 8 de dezembro. Consultado a 08.12.2017, em https://www.publico. pt/2017/12/08/politica/opiniao/a-vitoria-de-um-estado-adhoc-e-a-resistencia-da -sociedade-civil-1795248.

Norman, Sarah; Coles, Eve (2002), "Order Out of Caos? A Critical Review of the Role of Central, Regional, and Local Government in Emergency Planning in London”, International Journal of Mass Emergencies and Disasters, 20(3), 369-398.

Quarantelli, Enrico (org.) (1998), What is a Disaster? Perspectives on the Question. London: Routledge.

Rowe, Gene; Frewer, Lynn J. (2005), “A Typology of Public Engagement Mechanisms”, Science, Technology \& Human Values, 30(2), 251-290.

Somers, Margaret (2008), Genealogies of Citizenship - Markets, Statelessness and the Right to Have Rights. Cambridge: Cambridge University Press. 
Artigo recebido a 29.05.2018

Aprovado para publicação a 14.12.2018

\author{
Manuel João Ribeiro \\ Instituto Superior de Educação e Ciências de Lisboa (ISEC Lisboa) | Centro Europeu de Riscos \\ Urbanos (CERU) \\ Alameda das Linhas de Torres 179, 1750-142 Lisboa, Portugal \\ Contacto: manuel.ribeiro@iseclisboa.pt \\ ORCID: https://orcid.org/0000-0002-0639-0121
}

\section{Risk Governance Models. Comparative Analysis between Three National Civil Protection Systems}

Risk governance processes are important explanatory factors of public policies that States adopt in safety strategies. Starting from an initial question of which risk governance models prevail in the definition and characterization of civil protection systems, a theoretical-analytical proposal of four models was developed: directive, hierarchical, decentralized and cooperative. This ideal typical modeling was applied to the civil protection systems of the United Kingdom, France and Portugal, through a comparative analysis of their respective operational domains and dimensions. The conclusions of this research, comparing empirical analysis with the typological models created, constitute the purpose of this paper.

Keywords: citizenship; civil protection; public policies; risk governance.
Modèles de gestion de risque. Analyse comparative entre trois systèmes nationaux de protection civile

Les procédures de gestion de risque sont d'importants facteurs permettant d'expliquer les politiques publiques que les États adoptent dans leur quête de stratégies de sécurité. Partant d'une interrogation initiale cherchant à savoir quelle est ou quelles sont les formes de gestion de risque qui prévalent en matière de définition et de caractérisation des systèmes de protection civile, une proposition théorico-analytique a été développée qui repose sur quatre modèles: directif, hiérarchique, décentralisé et coopératif. Cette formulation, au caractère idéalo-typique, fut appliquée à l'étude des systèmes de protection civile du Royaume Uni, de la France et du Portugal, par le biais d'une analyse comparative des domaines en cause et des dimensions des opérations. Les résultats et les conclusions de ce travail d'investigation, confronté à l'analyse empirique avec les modèles typologiques créées, constitue la finalité de cet article.

Mots-clés: citoyenneté; gestion de risque; politiques publiques; protection civile. 
